\title{
Bagaço de uva da cultivar Merlot: atividade antibacteriana e antibiofilme contra Pseudomonas aeruginosa
}

\author{
Jéssica Andrade Gomes ${ }^{1}$, Milene Teixeira Barcia ${ }^{1}$, Jorge Alberto Vieira Costa ${ }^{1}$, \\ Gustavo Waltzer Fehrenbach ${ }^{1}$, Catiane Duarte Pacheco², Leandra Zafalon Jaekel² e \\ Karine Rigon Zimmer ${ }^{1}$
}

\author{
${ }^{1}$ Universidade Federal do Rio Grande - Escola de Química e Alimentos \\ Caixa Postal 474 - CEP 96203-900 Rio Grande - RS - E-mail: karorzimmer@gmail.com \\ ${ }^{2}$ Instituto Federal de Educação, Ciência e Tecnologia Sul - Rio-grandense - Curso Técnico de \\ Agroindústria \\ Avenida Leonel de Moura Brizola - 2501 - 96418-400 Bagé - RS
}

\begin{abstract}
RESUMO
A busca de compostos capazes de inibir o crescimento de bactérias clinicamente relevantes é de grande valia devido à escassez alarmante de agentes capazes de controlar infecções causadas por elas. Este trabalho teve como objetivo a busca de compostos com ação antibacteriana e antibiofilme a partir de bagaço de uva da cultivar Merlot. Os extratos foram obtidos utilizando como solventes água destilada e uma mistura água:etanol. 0 crescimento bacteriano e formação de biofilme foram avaliados pelo monitoramento da absorbância a 600 $\mathrm{nm}$ e pelo método do cristal violeta, respectivamente. Os extratos inibiram o crescimento de Pseudomonas aeruginosa, onde o primeiro apresentou $90 \%$ de inibição enquanto o segundo 52\%. Além disso, o extrato obtido da extração com água destilada foi capaz de inibir em 38\% o biofilme desta bactéria. A utilização de resíduos na busca por compostos antimicrobianos apresenta-se como uma alternativa interessante do ponto de vista tecnológico e ambiental.
\end{abstract}

Palavras-chave: resíduo, uva, inibição, antibacteriano, biofilme.

\section{INTRODUÇÃO}

O Brasil é um dos maiores produtores de resíduos agroindustriais, sendo as indústrias viníferas responsáveis por grande parte do descarte destes rejeitos no meio ambiente (ALONSO et al., 2002). O acúmulo desses resíduos na natureza gera danos ao equilíbrio ambiental. Deste modo, é importante buscar alternativas para aproveitamento desta matéria orgânica, que pode apresentar alto valor agregado (NIGAM, 2009). O bagaço de uva pode representar uma fonte promissora na busca de compostos capazes de inibir o crescimento e prevenir a formação de biofilme de bactérias de relevância clínica tais como $P$. aeruginosa. Pseudomonas aeruginosa é uma bactéria ubíqua e oportunista, sendo virulenta para diferentes hospedeiros incluindo plantas, nematódeos, insetos e mamíferos (KASZAB et al., 2011). Em humanos é considerada como um patógeno importante causando uma ampla gama de infecções. Os biofilmes são comunidades de micro-organismos encapsuladas em uma matriz composta predominantemente de substância extracelular polimérica (JAIN et al., 2007).

Universidade Estadual de Londrina - Rodovia Celso Garcia Cid, Pr 445, Km 380 - Campus Universitário Caixa Postal 10.011 CEP 86057-970 Centro de Ciências Exatas - Departamento de Bioquímica e Biotecnologia Fone +55 (43) 3371.4270 - biq@uel.br 


\section{SIMPÓSIO DE BIOQUÍMICA E BIOTECNOLOGIA}

\section{5 a 07 de agosto de 2015, Londrina - PR}

\section{VSIMBBTEC}

Londrina 2015

Este trabalho teve como objetivo buscar compostos com ação antibiofilme e antibacteriana a partir do bagaço de uva da cultivar Merlot.

\section{Material}

\section{MATERIAL E MÉTODOS}

As amostras de bagaço de uva Merlot foram obtidas do processo de vinificação da safra de fevereiro de 2015 cedidas pela Vinícola Peruzzo localizada na região de Bagé, Estado do Rio Grande do Sul. Utilizou-se como solventes para extrações água destilada (extrato 1) e mistura água:etanol $(1: 1, \mathrm{v} / \mathrm{v})$ (extrato 2).

\section{Preparação da amostra}

As amostras de bagaço de uva foram secas em estufa com circulação de ar a $50^{\circ} \mathrm{C}$ até obter umidade de $11 \%$. Após, foram trituradas em moinho (Multiuso) e armazenadas em ultrafreezer a $-80^{\circ} \mathrm{C}$ até o momento das análises.

\section{Extração dos compostos}

As amostras trituradas ( $2 \mathrm{~g}$ ) foram imersas em $20 \mathrm{~mL}$ de água destilada (extrato 1) e mistura água:etanol (1:1, v/v) (extrato 2) e mantidas em ultrassom durante $5 \mathrm{~min}$. Em seguida as amostras foram centrifugadas a $6000 \mathrm{~g}$ por $10 \mathrm{~min}$. Retirou-se o sobrenadante e o sedimento resultante foi submetido às mesmas extrações por mais duas vezes. Posteriormente, completouse o volume do extrato, com as respectivas soluções extratoras, em balão volumétrico até que se obtivesse $50 \mathrm{~mL}$ de solução. A amostra com extrator água foi congelada a $-80^{\circ} \mathrm{C}$ e posteriormente liofilizada. A solução com água e etanol foi submetida ao rota-evaporador durante $3 \mathrm{~h}$ (sendo $2 \mathrm{~h}$ sem adição de temperatura e $1 \mathrm{~h}$ a temperatura de $45^{\circ} \mathrm{C}$ ). Em seguida 0 extrato foi congelado a $-80^{\circ} \mathrm{C}$ e liofilizado. Os extratos secos foram congelados $\mathrm{a}-80^{\circ} \mathrm{C}$ até $\mathrm{O}$ momento das análises. Para a realização dos testes, os extratos secos foram ressuspendidos em água destilada a uma concentração de $10 \mathrm{mg} / \mathrm{mL}$ e filtrados em membrana de 0,22 $\mu \mathrm{m}$.

Avaliação do crescimento bacteriano

Pseudomonas aeruginosa UCBPP-PA14 (RAHME et al., 1995) foi cultivada em ágar LuriaBertani (LB, peptona $10 \mathrm{~g} / \mathrm{L}$, extrato de levedura $5 \mathrm{~g} / \mathrm{L}$ e $\mathrm{NaCl} 10 \mathrm{~g} / \mathrm{L}$ ) a $37^{\circ} \mathrm{C}$ durante $24 \mathrm{~h}$. Para os ensaios antimicrobianos e de formação de biofilme foi utilizada uma suspensão bacteriana em $\mathrm{NaCl}$ 0,9\% correspondendo a 1 na escala de McFarland ( $\left.3 \times 10^{8} \mathrm{UFC} / \mathrm{mL}\right)$. O crescimento bacteriano foi avaliado pelo monitoramento da absorbância a $600 \mathrm{~nm}$ (tempo zero e tempo 24 h). $O$ micro-organismo foi incubado a $37^{\circ} \mathrm{C}$ na presença de caldo LB e extrato (amostra tratada). Para o controle de crescimento (amostra não tratada) substitui-se o extrato por água destilada estéril. Neste ensaio foram igualmente realizados dois controles: um controle de esterilidade (contendo 3,5 mL de caldo LB) e um controle de cor do extrato (contendo 1,4 $\mathrm{mL}$ de $\mathrm{NaCl} 0,9 \%, 1,4$ de extrato e $0,7 \mathrm{~mL}$ de caldo LB).

Avaliação da atividade antibiofilme

O avaliação da atividade antibiofilme foi realizada segundo protocolo de Zimmer et al. (2013) utilizando $P$. aeruginosa UCBPP-PA14 (RAHME et al., 1995) como modelo formador de biofilme e tubos de vidro como superfície para a adesão bacteriana. Para o ensaio foram utilizados $1,4 \mathrm{~mL}$

Universidade Estadual de Londrina - Rodovia Celso Garcia Cid, Pr 445, Km 380 - Campus Universitário Caixa Postal 10.011 CEP 86057-970 Centro de Ciências Exatas - Departamento de Bioquímica e Biotecnologia Fone +55 (43) 3371.4270 - biq@uel.br 




\title{
V SIMPÓSIO DE BIOQUÍMICA E BIOTECNOLOGIA
}

\author{
05 a 07 de agosto de 2015, Londrina - PR
}

de suspensão bacteriana (1 na escala de McFarland), $1,4 \mathrm{~mL}$ de extrato e 0,7 de caldo LB (amostra tratada). Na amostra não-tratada, o extrato foi substituído por água destilada estéril. Neste ensaio foram igualmente realizados dois controles: um controle de esterilidade (contendo $3,5 \mathrm{~mL}$ de caldo LB) e um controle de cor do extrato (contendo $1,4 \mathrm{~mL}$ de $\mathrm{NaCl} 0,9 \%, 1,4$ de extrato e $0,7 \mathrm{~mL}$ de caldo LB). Os tubos foram incubados por $24 \mathrm{~h}$ a $37^{\circ} \mathrm{C}$. Em seguida, 0 conteúdo dos tubos foi retirado e estes foram lavados com $\mathrm{NaCl} 0,9 \%$ por 3 vezes para remoção das células planctônicas. Posteriormente o biofilme formado nos tubos foi fixado em estufa a $60^{\circ} \mathrm{C}$ por uma $1 \mathrm{~h}$. A camada de biofilme aderente foi corada utilizando cristal violeta $0,4 \%$ durante 15 min a temperatura ambiente. $O$ excesso de corante foi removido com água corrente até que a água fluísse incolor. $\mathrm{O}$ corante que permaneceu ligado ao biofilme nos tubos foi solubilizado por etanol absoluto e a absorbância foi mensurada a $570 \mathrm{~nm}$.

Análise estatística

Foram realizadas duas replicatas biológicas independentes $(n=3)$ sendo os resultados apresentados como média \pm desvio padrão. Para avaliação dos grupos (amostras não-tratada e tratada) foi utilizado o teste T de Student. Um $p \leq 0,05$ foi considerado como significativo.

\section{RESULTADOS E DISCUSSÃO}

Os extratos obtidos a partir do bagaço de uva da cultivar Merlot inibiram significativamente 0 crescimento da bactéria $P$. aeruginosa. O extrato 1 inibiu em $90 \%$ o crescimento enquanto o extrato 2 inibiu em 52\% o crescimento desta bactéria (Figura 1). Interessantemente, o extrato 1 foi igualmente capaz de inibir em $38 \%$ o biofilme de $P$. aeruginosa (Figura 2 ).



Figura 1 - Efeito dos extratos de bagaço de uva com água (extrato 1) e com água:etanol(1:1,v/v) (extrato 2) no crescimento da bactéria $P$. aeruginosa. Os valores médios \pm desvio padrão das duplicatas independentes são mostrados. *: representa uma diferença significativa em relação a amostra não tratada (teste T de Student, $p \leq 0,05$ ).

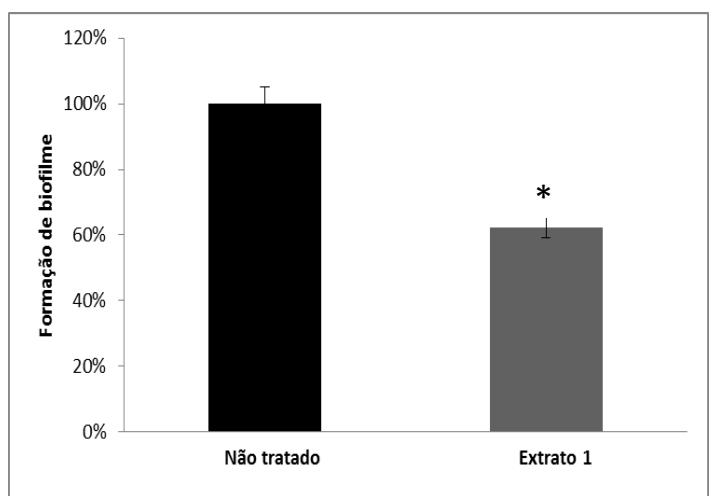

Figura 2 - Efeito do extrato de bagaço de uva com água (extrato 1) na formacão de biofilme da bacteria $P$. aeruginosa. Os valores médio \pm desvio padrão das duplicatas independentes são mostrados. *: representa uma diferença significativa em relação a amostra não tratada (teste $T$ de Student, $p \leq 0,05$ ).

Universidade Estadual de Londrina - Rodovia Celso Garcia Cid, Pr 445, Km 380 - Campus Universitário Caixa Postal 10.011 CEP 86057-970 Centro de Ciências Exatas - Departamento de Bioquímica e Biotecnologia Fone +55 (43) 3371.4270 - biq@uel.br 


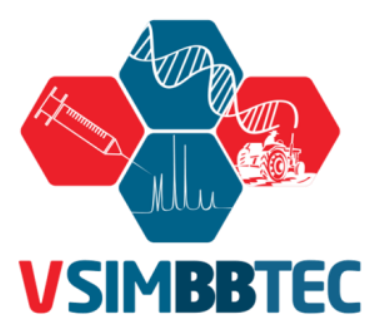

\title{
V SIMPÓSIO DE BIOQUÍMICA E BIOTECNOLOGIA
}

\author{
05 a 07 de agosto de 2015, Londrina - PR
}

O bagaço de uva tem sido comumente estudado por possuir potencial na obtenção de compostos com alto valor agregado. Esta matéria-prima vem sendo apontada como uma importante fonte de compostos com atividade biológica. Estudos já demonstraram que o bagaço de uva pode conter compostos como polifenois, ácidos graxos, ácidos cinâmico e benzoico e outros compostos que são de interesse para as indústrias farmacêutica, alimentícia e de cosméticos. Compostos com atividade antioxidante, antitumoral e anti-inflamatória já foram extraídos a partir deste resíduo (TORRES E BOBET 2001; DE CAMPOS, 2005). Além disso, Castro et al. (2006) mostraram o potencial de bagaço de uva como fonte de antocianidinas que apresentaram atividade antioxidante indicando essa matéria-prima como uma importante fonte de compostos bioativos.

\section{CONCLUSÕES}

Os resultados deste estudo demonstraram que os extratos obtidos do bagaço da uva Merlot apresentaram importante atividade antibacteriana e antibiofilme. Os extratos serão submetidos à purificação a fim de avaliar a natureza química do(s) composto(s) que apresentaram atividade biológica. A exploração de resíduos provenientes do processamento da uva mostra-se como uma alternativa promissora na busca por agentes capazes de controlar infeç̧ões bacterianas.

Agradecimento: A aluna Jéssica Gomes possui bolsa Ensino, Pesquisa, Extensão e Monitoria EPEM para desenvolvimento do trabalho.

Agências de Fomento: $\mathrm{CNPq}$

\section{REFERÊNCIAS}

ALONSO, A. M.; GUILLEN, D. A.; BARROSO, C. G.; PUERTAS, B.; GARCIA, A. Determination of Antioxidant Activity of Wine Byproducts and Its Correlation with Polyphenolic Content. Journal Agriculture Food Chemistry, v.50, p. 5832-5836, 2002.

CASTRO, X. U.; RUBIO, M. M.; BARQUERO, H.; MARTINEZ,G.G. Ultrasound-assisted Extraction of Polyphenols from Red-grape (Vitis vinifera) Residues. Engineering Faculty, Universidad de La Sabana, Chía, Colombia, 2006.

De CAMPOS, L.M.A.S. Obtenção de bagaço de uva cabernet sauvignon (Vitis vinífera): parâmetros de processo e modelagem matemática. Tese Universidade Federal de Santa Catarina, Programa de PósGraduação em Engenharia de Alimentos, 2005.

JAIN, A.; GUPTA, Y.; AGRAWAL, R.; KHARE, P.; JAIN, S. K. Biofilms -a microbial life perspective: a critical review. Critical Reviews in Therapeutical Drug Carrier Systems, 24: 393-443, 2007.

KASZAB, E.; SZOBOSZLAY, S.; DOBOLYI, C.; HAHN, J.; PÉK, N.; KRISZT, B. Antibioticresistance profiles and virulence markers of Pseudomonas aeruginosa strainsisolated from composts. Bioresour. Technol, 2011.

NIGAM, P.S. Production of bioactive secondary metabolites. In: Nigam PS, Pandey A (eds) Biotechnology for agro-industrial residues utilization. Springer, New York, 2009.

RAHME, L. G.; TAN, M. W.; LE, L.; WONG, S. M.; TOMPKINS, R. G.; CALDERWOOD, S. B.; AUSUBEL, F. M. Uso de modelo de planta hospeda para identificar Pseudomonas aeruginosa fatores de virulência. Proc Natl Acad Sci EUA, 1995.

TORRES, J. L.; BOBET, R. New flavanol derivatives from grape ( Vitis vinifera) byproducts. Antioxidant aminoethylthio-flavan-3-ol conjugates from a polymeric waste fraction used as a source of flavanols. Journal of Agricultural and Food Chemistry, 2001.

ZIMMER, K. R.; MACEDO, A. J.; GIORDANI, R. B.; CONCEIÇÃO, J. M.; NICASTRO, G. G.; BOECHAT, A. L.; BALDINI, R. L.; ABRAHAM, W. R.; TERMIGNONI, C. A. Steroidal molecule present in the egg wax of the tick Rhipicephalus (Boophilus) microplus inhibits bacterial biofilms. Environmental Microbiology, 2013.

Universidade Estadual de Londrina - Rodovia Celso Garcia Cid, Pr 445, Km 380 - Campus Universitário Caixa Postal 10.011 CEP 86057-970 Centro de Ciências Exatas - Departamento de Bioquímica e Biotecnologia Fone +55 (43) 3371.4270 - biq@uel.br 